Matching Interventions to Reading Needs: A Case for Differentiation

Jill S. Jones

North Carolina State University

Kristin Conradi

College of William \& Mary

Steven J. Amendum

University of Delaware

Corresponding Author:

Jill S. Jones

259 Bally Shannon Way

Apex, NC 27539

Phone: (919) 522-6597

Email: jsjones7@ncsu.edu 


\begin{abstract}
The purpose of this article is to highlight the importance of providing reading interventions that are differentiated and aligned with an individual student's most foundational reading need. The authors present profiles of different readers and suggest three principal areas for support: decoding words, reading at an appropriate rate, and comprehending text. In addition to describing differentiated interventions, related classroom instructional techniques are also recommended.
\end{abstract}

\title{
Teaser Text
}

In this article, we address how classroom teachers and literacy specialists can differentiate reading interventions in order to effectively target students' most critical needs and accelerate reading growth.

\section{Pause and Ponder}

Look at your student data. For your struggling readers, what are their chief needs? Which intervention activities would best match the chief needs of your students? Beyond activities presented in this article, what are some other instructional strategies and activities you think would be helpful? 


\section{Matching Interventions to Reading Needs: A Case for Differentiation}

Ensuring reading proficiency for all students is not only an individual classroom or school concern, but a national one. Currently, almost one third of fourth grade students are reading below the fourth-grade benchmark according to the National Assessment of Educational Progress (NCES, 2015). This sizeable percentage of struggling readers has garnered much attention, with large-scale efforts such as Response to Intervention put in place (RTI; Gersten et al., 2008), along with hundreds of research studies conducted to better understand how we can most effectively deliver reading interventions (see O’Connor \& Vadasy, 2011).

Although the sizeable number of students struggling has garnered significant research attention, problems persist. Some have some questioned the effectiveness of RTI (Balu et al., 2015) and others in the field wonder if we have adopted too many "quick fix" interventions that simply are ineffective (see Compton, Miller, Elleman, \& Steacy, 2014, p. 55). Reading interventions are expensive, both in terms of the teacher's time and the actual cost of materials (Amendum, Amendum, \& Almond, 2013), but despite accumulating evidence that children struggle with reading for different reasons (e.g., Compton et al., 2014; Riddle Buly \& Valencia, 2002; Spear-Swerling, 2015), most schools continue to group struggling readers together for intervention services.

In this paper, we argue for a differentiated approach. Based on data that suggests not all struggling readers need help in all areas of reading, we promote brief, systematic interventions targeting the students' most pressing need. We are motivated by a belief that too many interventions are inefficient and fail to accelerate readers' progress. 


\section{Background}

In our own work (Conradi, Amendum, \& Walkowiak, 2014), we examined reading data for over six thousand third-grade students who failed a high-stakes state reading comprehension test. Using a statistical procedure called latent profile analysis, we established five distinct profiles of readers (see Table 1). Though all students in our study failed the standardized comprehension test, their scores on other measures (targeting aspects of fluency and comprehension) varied considerably. Unlike previous research — that established a subtype of readers who could comprehend text despite weak fluency skills (see Riddle Buly \& Valencia, 2002) — our findings did not suggest this possibility. We suspect this is because our study only used grade-level texts for the assessments, whereas Riddle Buly and Valencia's study used texts deemed at participants" "instructional" levels.

Our analyses yielded five distinct profiles with three particular areas of need. A small group of students $(8.1 \%)$ in two profiles struggled to decode grade-level texts with appropriate accuracy. A larger group of students (28.5\%) could decode with fair accuracy $(91.9 \%)$ and lacked automaticity. Finally, the largest group of students $(63.3 \%)$, in the remaining two profiles, read with accuracy and rates ranging from proficient to excellent, but still struggled with comprehension. Motivated to develop quick interventions highlighting students' most pressing needs, we determined three areas of need from our analyses: decoding words accurately, reading texts with automaticity, and actively making meaning while reading.

This research stands counter to what occurs in many interventions. The majority of students in our study do not need support with decoding, suggesting that "balanced" interventions - which incorporate elements of word study, fluency practice, and attention to comprehension - might be a waste of their time. Only the small group of students still struggling 
with accuracy needs specific decoding intervention work; and it is quite possible that after receiving instruction in this area, some students will not need additional support.

We acknowledge from the onset a possible danger in our framework. In promoting brief interventions focusing on certain targeted skills, we do not mean to deny the complexity of reading. The underlying reasons students struggle with reading can be multifaceted and complex. Factors such as vocabulary (Goodwin \& Perkins, 2015), motivation to read (Jang, Conradi, McKenna, \& Jones, 2015), and the ability to strategize while reading (Boulware-Gooden, Carreker, Thornhill, \& Joshi, 2007) all influence students' abilities to successfully read texts. Our choice to target three selected areas was informed by assessments readily available to teachers and by evidence yielded in previous studies.

\section{How Do I Identify the Fundamental Need?}

In supporting students who struggle with independent text comprehension, we want to consider what might be preventing them from being successful. The issue may be automaticity. If students are still struggling to decode with accuracy or automaticity, they might lack the cognitive resources necessary to comprehend the text (LaBerge \& Samuels, 1974). However, although rate is necessary for comprehension, it is hardly sufficient. Students who struggle with comprehension, despite having adequate fluency, need scaffolded opportunities to strategize.

To determine what struggling readers most need, teachers and specialists should consider readily available data, such as DIBELS (Good, Kaminski, \& Dill, 2007) or curriculum-based measures (e.g. Hosp, Hosp, \& Howell, 2007). We recommend adopting a model based on an updated version of Stahl and colleagues' (1999) Cognitive Model (McKenna \& Stahl, 2015). As shown in Figure 1, one works "backwards" to consider whether students can successfully comprehend grade-level text. If so, no intervention is needed. If not, the next step is to determine 
whether students read with adequate rate (see grade-level expectations in Hasbrouck \& Tindal, 2006). If rate is adequate, then students need support with comprehension only. If rate is inadequate, the final step is to determine whether students need support to actually decode words or just to read them with more automaticity.

After determining the fundamental area of need, we suggest teaching targeted reading skills in small-group or individual interventions. These intervention lessons should be brief and systematic. In Table 2, we present possible lesson formats. Of note: although each lesson does include some time in connected text, it is hardly enough — so we underscore the need for a larger classroom context where extended reading occurs daily (e.g., Hiebert, 2015).

\section{What Can I Do for Students with Decoding Needs?}

Of the three reading needs determined, the most fundamental is decoding. A student's inability to recognize words accurately compromises comprehension (Catts, 2009). In our study, only a small percentage of students $(8.1 \%)$ exhibited significant difficulty decoding words in text.

\section{Determining Word Recognition Needs}

Students struggle with word recognition for different reasons. Some might struggle to blend three- and four- sound words (CVC, CVCC, CCVC words, such as rug, fish, plop), whereas others might struggle with multisyllabic words (such as sandwich and revolution). To ascertain specific needs, we recommend administering a decoding inventory (e.g., McKenna, Walpole, \& Jang, 2016). Students who have trouble decoding need explicit word-level instruction (Spear-Swerling, 2015); below we provide some possible instructional activities. 


\section{Blending}

To build word recognition, teachers should model how to blend words. For example, for students having difficulty with r-controlled vowels, using the order of $a r, o r, i r, e r$, and $u r$, teachers or specialists should model the sounds and how to blend them in words such as dark, fort, and third (Walpole \& McKenna, 2009). Then, opportunities to practice reading individual words and text containing words with these patterns should be provided.

\section{Morphology}

The majority of students who have difficulty with decoding later in elementary school struggle to read multisyllabic words accurately (Bhattacharya \& Ehri, 2004). Morphology instruction should help students with needs in this area. Morphemes are the smallest meaningbearing parts of words, which commonly include the prefix, the root, and the suffix (Cunningham, 1998). This practice moves beyond simply supporting decoding and also leads to better vocabulary and comprehension (Goodwin \& Perkins, 2015). A recommended instructional approach is DISSECT (Lenz \& Hughes, 1990), an acronym for a morphological analysis strategy: Discover the context of the word in the sentence, Isolate the prefix, Separate the suffix,

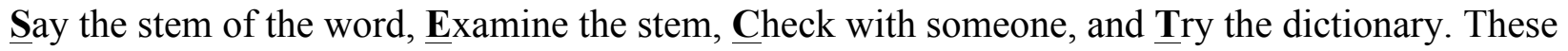
steps should be explicitly modeled and students should receive feedback.

A related approach involves teaching complex word families. Different from a typical word family (e.g., bake, cake, take), complex word families are derivatives of a root word (Hiebert, 2013). Hiebert suggests there are 2,500 core complex morphological word families students should know. Teaching students a root word and its derivatives builds students' word knowledge and understanding of relationships between words. Students can create word webs with the root word in the center and derivations around the root (Hiebert, 2013). For example, 
derivations of the word hope can be introduced such as hopes, hoping, hoped, hopeful, hopeless. The recognition of smaller parts of words (e.g., prefixes, suffixes, and roots) should assist students with future encounters of these components.

\section{What Can I Do for Students Who Need to Improve Reading Rate?}

Fluency encompasses several different components including accuracy, automaticity, prosody, and stamina (Hiebert, 2015; Young \& Rasinski, 2009). More than one quarter of students in our study (28.5\%) were able to decode fairly proficiently, but without automaticity. Since the ultimate goal of reading is making meaning, we caution against an overemphasis on reading rate; however, a lack of automaticity might contribute to struggles with comprehension (e.g., LaBerge \& Samuels, 1974). Although intervention for reading rate is necessary for some students, the underlying message should not be that rate is central. Instead, rate should be improved to ensure that students can devote attention to thinking while reading (Mesmer, Mesmer, \& Jones, 2014; Walpole \& McKenna, 2007). Consequently, we caution against reading for one-minute time periods and suggest the use of extended passages and texts instead.

\section{Repeated Readings}

Students need practice reading connected text to improve their reading rates. One activity involves repeated readings (Kuhn, 2005; Samuels, 1979). This instructional intervention consists of reading the same text three or four times, while the number of words read per minute is measured and charted on a graph to track progress. Although repeated readings lead to increased reading rate (Kuhn, 2005), two important components need to be considered. The first consideration is the type of text used. Some recommend narrative texts (Mesmer et al., 2014), whereas others suggest informational texts because they also build content knowledge (Hiebert, 2000). Second, students need to receive corrective feedback prior to rereading the passage. The 
teacher should identify difficult phrases, model correct phrasing, and ask students to repeat the correct phrases (Begeny, 2011).

Another way to accomplish repeated readings of a text is by having students engage in Readers Theatre (Young \& Rasinski, 2009). In preparing to perform the meaning of a text for an audience, students repeatedly read their parts of a script, leading to an increase in both accuracy and automaticity. In addition, engaging in Readers Theatre can lead to increased motivation (Young \& Rasinski, 2009).

\section{Echo and Choral Reading}

Echo and choral reading practices also build students' accuracy and reading rate (Samuels, 1979). In echo reading, the teacher reads a selection of text first, while students follow along in the text. Students then read the same text with the rate and expression modeled by the teacher. This process continues until the entire selection of text has been read (Walpole, McKenna, \& Philippakos, 2011). In choral reading, the teacher does not read the text in advance. Instead, the teacher and the students read the text simultaneously or the students work together in groups to read the text at the same time (Walpole et al., 2011).

\section{What Can I Do for Students Who Have Trouble Comprehending?}

The ultimate goal of reading is to make meaning from the text. Although all of the students in our study struggled with comprehension, more than half the students $(63.3 \%)$ had great difficulty with comprehension despite appearing proficient in other areas. This finding was consistent with many of our own experiences in the classroom. As former elementary teachers, we are familiar with students who can decode almost any text, but who struggle to make sense of what they read. Some refer to students in this category as "word callers"-suggesting students call out the words, but do not engage in the real thinking necessary to adequately comprehend 
(Cartwright, 2010). Others propose these students might be victims of a testing era that has all too often overemphasized the importance of speed, at the cost of minimizing comprehension (Deeney, 2010; Samuels, 2007).

Instead of spending intervention time on foundational fluency skills, students in this group need significant time in text. Perfetti (1985) acknowledged the importance of moving beyond fluency alone when he defined reading as "thinking guided by print" (as cited by Vaughn et al., 2013). For students who already have adequate decoding skills and automaticity, but who struggle with comprehension, cultivating text-based thinking should be the intervention focus.

Unlike needs in word recognition and rate, we lack fine-tuned comprehension measures to help pinpoint students' exact comprehension needs. In fact, research has consistently demonstrated difficulties with materials attempting to measure these needs (Duke, 2005; Schell \& Hanna, 1981). Unfortunately, this means we have little data to inform comprehension-focused interventions. The practices we provide below, though general, should contribute to improved text comprehension.

\section{Questioning to Build Metacognition}

Expert readers think and reason while reading. To help build metacognitive skills, we strongly recommend moving away from decontextualized comprehension strategy instruction. Though expert readers are strategic, current practices for teaching strategies too often move students away from the text's content, with teachers often over-teaching strategies when students only need to be reminded to use them (Willingham, 2006). Researchers in one study directly compared the benefits of strategy instruction with a more simple approach of questioning the text (McKeown, Beck, \& Blake, 2009). At various stopping points, teachers using the strategies approach would stop, use a strategy, and remind students how to apply that strategy. On the other 
hand, teachers using the content approach would stop and initiate a general, open-ended question such as "What is going on here?" or "How does all this connect with what we read earlier?" (p. 223). Students in this latter group significantly outperformed students in the strategies group.

We suggest following a similar approach, by keeping the focus on the text and providing students with ample time to monitor comprehension. This approach starts with the interventionist modeling the process, which Duffy (2014) calls explaining "the secrets" of reading (p. 41). This modeling should be intentional and focused on parts of the text that the teacher suspects might prove difficult for students. In addition, this modeling of strategic thinking must be brief to avoid distracting students from the real purpose of making sense of the text. For example, the group might whisper or silently read a section and the teacher could stop and say, "Hmmm...it's helpful for me if I stop and review what's going on here. So far, I've learned that the character, Peter, is shy and nervous about starting school. I know this because..."

After successive modeling, the teacher can shift to questioning using prompts such as: "What do we know so far?" "How does this make sense?" "Is this consistent with what we know about the character so far?" By providing students with questions - and eventually moving to where students ask the questions themselves — we promote their metacognitive skills and build their independence as readers (Afflerbach, Cho, Kim, Crassas, \& Doyle, 2013). To help students learn to question, we recommend providing questions on laminated bookmarks (see Figure 2).

\section{Using Graphic Organizers to Build Inference Skills}

Many students who are fluent, but struggle with comprehension, have difficulty with a specific aspect of comprehension: making inferences (Cain \& Oakhill, 1999). The ability to generate inferences is difficult because it requires a reader be able to think across text (or texts), 
or it requires the reader to connect something in the text with expected background knowledge (Oakhill, Cain, \& Elbro, 2015).

To help students with inferencing, we adapted Oakhill and colleagues' graphic organizer that can be used with a variety of texts (see Figure 3). The sentence frames remind students that reading often requires connecting pieces of information, whether those pieces are provided exclusively in the text, or whether we have to use knowledge from previous experiences or other texts to help us understand. As with questioning, this practice should occur within the context of the specific text being read.

\section{Frontloading Necessary Background Knowledge}

We acknowledge that there are instances where a student could be a strategic, fluent reader, but could still struggle with comprehension. One reason could be that the background knowledge the student brings to the text might be inconsistent with the expectations of the author. We prefer to move away from language that promotes the idea that some students have "low" background knowledge and instead favor the idea that the type of knowledge valued in school is not always consistent with the wealth of knowledge students bring (Moll, Amanti, Neff \& Gonzalez, 1992).

In these situations, it is likely that questioning the text will not help. The author has assumed the reader knew something---and without that knowledge, the reader has too many gaps to fill in order to make sense of it (Neuman, Kaefer, \& Pinkham, 2014). The best way to prevent this from occurring is for students to read frequently and widely and for teachers in early grades to provide more time for content area instruction (Willingham, 2006).

If, within an intervention setting, the concern is a lack of sufficient school-valued background knowledge, the teacher might consider using more content-rich, nonfiction texts. 
The teacher should consider what types of knowledge would be most valuable for making sense of that specific text. For example, if students are about to read a passage that includes several references to an urban setting, the teacher might anticipate frontloading information about cities for the students to adequately visualize and infer while reading. The trick is to provide necessary information without taking time from students' reading of the text. We encourage borrowing some strategies and activities from SIOP recommendations (Echevarría, Vogt \& Short, 2010), such as employing multimedia or images (Neuman et al., 2014).

\section{What Can I Do at the Whole-Class Level?}

The intervention ideas discussed up to this point will only be effective if students are also engaged in classrooms that provide rich literacy instruction. Below, we share some key instructional practices for Tier 1 literacy instruction (Mesmer \& Mesmer, 2008).

\section{Classroom Practices for Word Recognition}

Whole-class reading instruction should include systematic word study instruction. This type of word study instruction should mirror students' development (e.g., Ehri, 2005) and build students' knowledge of words from understanding phonemic, then orthographic, and finally morphemic word structures (Bear, Invernizzi, Templeton \& Johnston, 2012). For example, in one framework, students progress from emergent and early reading stages to final stages based on derivational relations of Greek and Latin root words (Bear et al., 2012). Such a framework meets the needs of students at varied levels of reading development and is systematic in the presentation of skills to be acquired - a hallmark of effective word study programs (NICHHD, 2000). 


\section{Classroom Practices for Building Fluency}

Shared reading of high quality text can be used to build fluency across the grade-level span in elementary schools. Though many primary grade teachers are familiar with shared reading to build beginning literacy skills (Parkes, 2000), this model can also be used to support the reading of challenging texts (e.g., Stahl, 2012). In shared reading, the teacher and students typically read chorally, with students first reading a text in a supportive environment while gaining confidence (Tierney \& Readence, 2005). This type of reading can also link fluency instruction and comprehension development; teacher-led modeling of fluency (prosody, rate, and accuracy), which can positively affect comprehension (Benjamin \& Schwanenflugel, 2010).

\section{Classroom Practices for Building Comprehension}

One effective classroom practice for building students' comprehension is the use of daily, high-quality read alouds of challenging texts. Read alouds afford students a variety of contexts where comprehension strategies can be modeled, as well as exposure to new vocabulary and new content. Texts for daily read alouds should be carefully chosen - the goal is to use text above students' grade level readability, but still conceptually accessible. Cunningham (2005) suggests using texts two to three grade levels above students' reading level.

We have often seen teachers capitalize on comprehension strategy instruction during read alouds. Although it is important to model strategy use, we caution against spending too much time on it. Quick modeling during reading yields better outcomes than a prolonged modeling and discussion (see McKeown et al., 2009, for more information). When choosing strategies, we recommend limiting to key evidence-based strategies (inference making, comprehension monitoring, and understanding text structure) that are central to understanding the text (Cain \& Oakhill, 2009). 


\section{Putting It All Together}

Too many students in U.S. schools continue to struggle with reading. Research has already established that students struggle with reading for different reasons. In order to best meet students' needs and capitalize on intervention time, classroom teachers and literacy specialists should develop targeted interventions closely matched to students' reading needs. In this article, we presented five different profiles, aligned to three specific foundational needs. Matched intervention ideas targeting word recognition, reading rate, and comprehension were presented. We maintain the need for differentiated, efficient, and focused interventions in order to expedite reading progress. Beyond interventions, effective whole class literacy instructional practices were also recommended. Our hope is that teachers and specialists can use this information to meet the specific needs of students, and that this, in turn, will lead to accelerated reading progress and opportunities for all of our readers to engage successfully with interesting, challenging, and rigorous texts.

\section{Take Action!}

1. Choose a student and analyze his/her reading assessment data to determine the student's strengths and weaknesses.

2. Determine the most foundational reading skill need of the student.

3. Select an intervention matched to the foundational skill and design an appropriate lesson.

4. After implementing for at least three weeks, reflect on the effectiveness of the intervention. Is the student making progress?

5. Think about your whole class. Which instructional practices can be implemented to address their needs? 


\section{References}

Afflerbach, P., Cho, B.-Y., Kim, J.-Y., Crassas, M.E., \& Doyle, B. (2013). Reading: What else matters besides strategies and skills? The Reading Teacher, 66, 440-448.

Amendum, S. J., Amendum, E., \& Almond, P. (2013). One Dy I Kud Not Red a Book Bot Naw I Can: One English learner's progress. The Reading Teacher, 67, 59-69. doi: 10.1002/TRTR.1183

Balu, R., Zhu, P., Doolittle, F., Schiller, E., Jenkins, J., \& Gersten, R. (2015). Evaluation of response to intervention practices for elementary school reading.

Bear, D.R., Invernizzi, M., Templeton, S., \& Johnston, F. (2012). Words their way: Word study for phonics, vocabulary, and spelling instruction (5th ed.). Upper Saddle River, NJ: Pearson/Prentice Hall.

Begeny, J.C. (2011). Effects of the Helping Early Literacy with Practice Strategies (HELPS) reading fluency program when implemented at different frequencies. School Psychology Review, 40, 149-157.

Benjamin, R.G., \& Schwanenflugel, P.J. (2010). Text complexity and oral reading prosody in young readers. Reading Research Quarterly, 45, 388-404.

Bhattacharya, A. \& Ehri, L.C. (2004). Graphosyllabic analysis helps adolescent struggling readers read and spell words. Journal of Learning Disabilities, 37(4), 331-348.

Boulware-Gooden, R., Carreker, S., Thornhill, A., \& Joshi, R. (2007). Instruction of metacognitive strategies enhances reading comprehension and vocabulary achievement of third-grade students. The Reading Teacher, 61, 70-77. 
Cain, K., \& Oakhill, J.V. (1999). Inference making ability and its relation to comprehension failure in young children. Reading and Writing: An Interdisciplinary Journal, 11, 489503.

Cain, K., \& Oakhill, J. (2009). Reading comprehension development from 8 to 14 years: The contribution of component skills and processes. In R.K. Wagner, C. Schatschneider, \& C. hythian-Sence (Eds.), Beyond decoding: The behavioral and biological foundations of reading comprehension (pp. 143-175). New York: Guilford Press.

Cartwright, K.B. (2010). Word callers: Small-group and one-to-one interventions for children who "read" but don't comprehend. Portsmouth, NH: Heinemann.

Catts, H.W. (2009). The narrow view of reading promotes a broad view of comprehension. Language, Speech, and Hearing Services in Schools, 40(2), 178-183.

Compton, D.L., Miller, A.C., Elleman, A.M., \& Steacy, L.M. (2014). Have we forsaken reading theory in the name of "quick fix" interventions for children with reading disability?. Scientific Studies of Reading, 18(1), 55-73.

Conradi, K., Amendum, S.J., \& Walkowiak, T. (2014, July). Reading profiles of third graders: A latent profile analysis. Interactive paper presented at the meeting of the Society for the Scientific Study of Reading, Santa Fe, NM.

Cunningham, A.E. (2005). Vocabulary growth through independent reading and reading aloud to children. In E.H. Hiebert \& M.L. Kamil (Eds.), Teaching and learning vocabulary: Bringing research to practice (pp. 45-67). Mahwah, NJ: Erlbaum.

Cunningham, P.M. (1998). The multisyllabic word dilemma: Helping students build meaning, spell, and read "big” words. Reading and Writing Quarterly, 14(2), 189-218. doi: $10.1080 / 1057356980140204$ 
Deeney, T.A. (2010). One-minute fluency measures: Mixed messages in assessment and instruction. The Reading Teacher, 63, 440-450.

Duffy, G.G. (2014). Explaining reading: A resource for explicit teaching of the Common Core Standards (3rd ed.). New York: Guilford Press.

Duke, N.K. (2005). Comprehension of what for what: Comprehension as a non-unitary construct. In S. Paris \& S. Stahl (Eds.), Current issues in reading comprehension and assessment (pp. 93-104). Mahwah, NJ: Erlbaum.

Echevarría, J., Vogt, M., \& Short, D.J. (2010). Making content comprehensible for elementary English learners: The SIOP model (4th ed.). Boston: Allyn \& Bacon.

Ehri, L.C. (2005). Learning to read words: Theory, findings, and issues. Scientific Studies of Reading, 9, 167-188. doi: 10.1207/s1532799xssr0902_4

Gersten, R., Compton, D., Connor, C.M., Dimino, J., Santoro, L., Linan-Thompson, S., \& Tilly, W.D. (2008). Assisting students struggling with reading: Response to Intervention and multi-tier intervention for reading in the primary grades. A practice guide. (NCEE 20094045). Washington, DC: National Center for Education Evaluation and Regional Assistance, Institute of Education Sciences, U.S. Department of Education. Retrieved from http://ies.ed.gov/ncee/wwc/ publications/practiceguides/.

Good, R.H., \& Kaminski, R.A., \& Dill, S. (2007). DIBELS® Oral Reading Fluency. In R. H. Good \& R. A. Kaminski (Eds.), Dynamic Indicators of Basic Early Literacy Skills $\left(6^{\text {th }}\right.$ ed.). Eugene, OR: Institute for the Development of Educational Achievement. Retrieved from http://dibels.uoregon.edu/

Goodwin, A.P., \& Perkins, J. (2015). Word detectives: Morphological instruction that supports academic language. The Reading Teacher, 68(7), 510-523. 
Hasbrouck, J., \& Tindal, G.A. (2006). Oral reading fluency norms: A valuable assessment tool for reading teachers. The Reading Teacher, 59(7), 636-644.

Hiebert, E.H. (2000). Quick Reads Family of Products. Retrieved from http://textproject.org/classroom-materials/students/commercially-available-products powered-by-text/quickreads-family-of-products/

Hiebert, E.H. (2013). Core vocabulary and the challenge of complex text. In S. Neuman \& L. Gambrell (Eds.), Quality Reading Instruction in the Age of Common Core Standards. Newark, DE: IRA.

Hiebert, E.H. (Ed.) (2015). Teaching stamina and silent reading in the digital-global age. Santa Cruz, CA: TextProject, Inc.

Hosp, M.K., Hosp, J.L., \& Howell, K.W. (2007). The ABCs of CBM: A practical guide to curriculum-based measurement. New York: Guilford Press.

Jang, B.G., Conradi, K., McKenna, M.C., \& Jones, J.S. (2015). Motivation: Approaching an elusive concept through the factors that shape it. The Reading Teacher, 69, 239-247. DOI:10.1002/trtr.1365

Kuhn, M. (2005). A comparative study of small group fluency instruction. Reading Psychology, 26, $127-146$.

LaBerge, D., \& Samuels, S.J. (1974). Toward a theory of automatic information processing in reading. Cognitive Psychology, 6, 293-323.

Lenz, K.B., \& Hughes, C.A. (1990). A word identification strategy for adolescents with learning disabilities. Journal of Learning Disabilities, 23(3), 149-158.

McKenna, M.C., \& Stahl, K.A.D. (2015). Assessment for reading instruction ( $^{\text {rd }}$ ed.). New York: Guilford Press. 
McKenna, M.C., Walpole, S., \& Jang, B.G. (2016). Validation of the Informal Decoding Inventory. Advance Online Publication. Assessment for Effective Intervention.

McKeown, M.G., Beck, I.L., \& Blake, R.G.K. (2009). Rethinking reading comprehension instruction: A comparison of instruction for strategies and content approaches. Reading Research Quarterly, 44, 218-253. doi: 10.1598/rrq.44.3.1

Mesmer, H.A.E., Mesmer, E., \& Jones, J. (2014). Reading intervention in the primary grades: A common-sense guide to RTI. New York: Guilford Press.

Mesmer, E.M., \& Mesmer, H.A.E. (2008). Response to intervention: What teachers of reading need to know. The Reading Teacher, 62, 280-290.

Moll, L.C., Amanti, C., Neff, D., \& Gonzalez, N. (1992). Funds of knowledge for teaching: Using a qualitative approach to connect homes and classrooms. Qualitative Issues in Educational Research, 31, 132-141. doi:10.1080/00405849209543534

National Center for Education Statistics. (2015). The nation's report card: 2015 Mathematics and Reading assessments . (NCES 2015-136). Washington, D.C.: Institute of Education Sciences, U.S. Department of Education.

Neuman, S.B., Kaefer, T., \& Pinkham, A. (2014). Building background knowledge. The Reading Teacher, 68(2), 145-148.

NICHHD. (2000). Report of the National Reading Panel. Teaching children to read: An evidence-based assessment of the scientific research literature of reading and its implications for reading instruction: Reports of the subgroups. Washington D.C.: National Institute of Child Health and Development.

Oakhill, J., Cain, K., \& Elbro, C. (2015). Understanding and teaching reading comprehension: A handbook. New York: Routledge. 
O’Connor, R., \& Vadasy, P., (Eds.). (2011). Handbook of reading interventions. New York: Guilford Press.

Parkes, B. (2000). Read it again! Revisiting shared reading. Portland, ME: Stenhouse.

Perfetti, C. (1985). Reading ability. New York, NY: Oxford University Press.

Riddle Buly, M. \& Valencia, S.W. (2002). Below the bar: Profiles of students who fail state assessments. Educational Evaluation and Policy Analysis, 28(4), 315-333. Retrieved from http://www.jstor.org/stable/3594166.

Samuels, S.J. (1979). The method of repeated readings. The Reading Teacher, 32(4), 403-408.

Samuels, S.J. (2007). The DIBELS tests: is speed of barking at print what we mean by reading fluency? Reading Research Quarterly, 42(4), 563-566.

Schell, L.M., \& Hanna, G.S. (1981). Can informal reading inventories reveal strengths and weaknesses in comprehension subskills? The Reading Teacher, 35, 263-268.

Spear-Swerling, L. (2015). Common types of reading problems and how to help children who have them. The Reading Teacher, 69(5), 513-522.

Stahl, K.A.D. (2012). Complex text or frustration-level text: Using shared reading to bridge the difference. The Reading Teacher, 66(1), 47-51. doi: 10.1002/trtr.01102

Stahl, S.A., Kuhn, M.R., \& Pickle, J.M. (1999). An educational model of assessment and targeted instruction for children with reading problems. In D.H. Evensen \& P. Mosenthal (Eds.), Reconsidering the role of the reading clinic in a new age of literacy (pp. 249272). Stamford, CT: JAI Press.

Tierney, R.J., \& Readence, J.E. (2005). Reading strategies and practices: A compendium (6 ${ }^{\text {th }}$ ed.). Boston: Allyn \& Bacon. 
Vaughn, S., Roberts, G., Klingner, J.K., Swanson, E.A., Boardman, A., Stillman-Spisak, S.J., \& Leroux, A.J. (2013). Collaborative strategic reading: Findings from experienced implementers. Research on Educational Effectiveness, 6, 137-163.

Walpole, S. \& McKenna, M.C. (2007). Differentiated reading instruction: Strategies for the primary grades. New York: Guilford Press.

Walpole, S., \& McKenna, M.C. (2009). How to plan differentiated reading instruction: Resources for grades K-3. New York: Guilford Press.

Walpole, S., McKenna, M.C., \& Philippakos, Z. (2011). Differentiated reading instruction in grades 4 and 5: Strategies and resources. New York: Guilford Press.

Willingham, D.T. (2006). The usefulness of brief instruction in reading comprehension strategies. American Educator, Winter, 39-45, 50.

Young, C., \& Rasinski, T. (2009). Implementing reader's theater as an approach to classroom instruction. The Reading Teacher, 63(1), 4-13. doi: 10.1598/RT.63.1.1 


\section{More to Explore}

Find additional student activities for decoding, fluency, and comprehension at http://www.fcrr.org/for-educators/sca.asp

Explore links and modules for building instructional capacity at http://comprehensivereadingsolutions.com/category/grades-k-5/

Find useful classroom reading materials at http://textproject.org/classroom-materials/ 
Table 1

Reading Profiles

Profile with Description

$\%$ of Primary Need

Students

Severely Inadequate Decoders

(could not access grade-level text at all; read with 38.0\% accuracy and rate of 7 words per minute)

\section{Poor Decoders}

(read grade-level text, on average, with $78.4 \%$ accuracy and rate of 32 words per minute)

Non-Automatic Decoders

(read grade-level text with $91.9 \%$ accuracy, but slow rate of 56 words per minute)

\section{Adequate Decoders}

(read grade-level text with $96.0 \%$ accuracy, rate of 82 words per minute, and did well on some comprehension measures)

\section{Unexplained Poor Comprehenders}

(read grade-level text with excellent accuracy of $97.8 \%$, rate of 120 words per minute, and did well on some comprehension measures)
1.6

6.5

Word

Recognition

28.5

Reading Rate

48.5

14.8

Note. All students failed to meet comprehension expectations on a state reading test administered in the fall 
Table 2

Example Decoding Lesson on Multisyllabic Words

\begin{tabular}{|c|c|c|}
\hline Focus & Activity & $\begin{array}{l}\text { Time } \\
\text { Frame }\end{array}$ \\
\hline $\begin{array}{l}\text { Model New } \\
\text { Word Pattern }\end{array}$ & $\begin{array}{l}\text { Teacher models how to break a word into different syllable parts. } \\
\text { For example, teacher breaks the word section into sec-tion and } \\
\text { models how to say each part and blend the parts into the whole } \\
\text { word. }\end{array}$ & $\begin{array}{l}2 \\
\text { minutes }\end{array}$ \\
\hline $\begin{array}{l}\text { Guided } \\
\text { Practice }\end{array}$ & $\begin{array}{l}\text { Teacher and students practice dividing additional words into parts. } \\
\text { (ex. happen, tablet, ladder, napkin, ponder) }\end{array}$ & $\begin{array}{l}3 \\
\text { minutes }\end{array}$ \\
\hline $\begin{array}{l}\text { Independent } \\
\text { Practice }\end{array}$ & $\begin{array}{l}\text { Students each receive a set of word cards with two syllable words. } \\
\text { Then, students read the words individually. Teacher records } \\
\text { whether students segment the words and read the whole words } \\
\text { correctly, or whether they need more support. }\end{array}$ & $\begin{array}{l}5 \\
\text { minutes }\end{array}$ \\
\hline $\begin{array}{l}\text { Text } \\
\text { Application }\end{array}$ & $\begin{array}{l}\text { Students read a passage with both monosyllabic and two-syllable } \\
\text { words. Students read individually while teacher listens to offer } \\
\text { support and observes strategies being used. Then, teacher asks } \\
\text { students to share two-syllable words in the text and how they } \\
\text { figured them out. }\end{array}$ & $\begin{array}{l}5 \\
\text { minutes }\end{array}$ \\
\hline
\end{tabular}

Example Reading Rate Lesson Plan

\begin{tabular}{lll}
\hline Focus & Activity & $\begin{array}{l}\text { Time } \\
\text { Frame }\end{array}$ \\
\hline $\begin{array}{l}\text { Model Reading } \\
\text { Fluently }\end{array}$ & $\begin{array}{l}\text { Teacher explains students need to read the way they talk - not } \\
\text { too fast or too slow. Teacher models different ways of reading } \\
\text { and asks the students to reflect on the rates. }\end{array}$ & $\begin{array}{l}\text { minutes } \\
\text { mate }\end{array}$
\end{tabular}

Guided Practice Teacher sets initial comprehension focus for passage to be read. 5 (i.e., "Now we will read about snakes. As you read, pay attention minutes to new things you learn about snakes.") Students then read the text together out loud in a choral fashion so the teacher can lead the reading at an appropriate rate. Teacher then says, "Let's read it one more time with a partner. This time, pay special attention to what you learn about how a snake's anatomy serves him well.") Students reread the text with a partner (one or two times).

Comprehension Teacher asks students to discuss the text. This is important to help students understand the overall purpose for reading at an efficient rate is to help them comprehend the meaning of the 5 text. 
Example Comprehension Lesson Plan

\begin{tabular}{|c|c|c|}
\hline Focus & Activity & $\begin{array}{l}\text { Time } \\
\text { Frame }\end{array}$ \\
\hline $\begin{array}{l}\text { Introducing } \\
\text { Text/Activating } \\
\text { Background } \\
\text { Knowledge }\end{array}$ & Teacher should review text from the prior day. & $\begin{array}{l}1-2 \\
\text { minutes }\end{array}$ \\
\hline $\begin{array}{l}\text { Review } \\
\text { Comprehension } \\
\text { Strategy }\end{array}$ & $\begin{array}{l}\text { Having previewed the text already, teacher should point out } \\
\text { a comprehension strategy students might need for the } \\
\text { specific text and remind them to use it. For example, "In } \\
\text { this section, we will learn about the main character's house. } \\
\text { It's helpful to visualize as you read, by making a picture in } \\
\text { your mind." }\end{array}$ & $\begin{array}{l}2 \\
\text { minutes }\end{array}$ \\
\hline $\begin{array}{l}\text { Provide Focus and } \\
\text { Vocabulary } \\
\text { Instruction (if } \\
\text { nonfiction) }\end{array}$ & $\begin{array}{l}\text { Teacher should set a focus for reading. (e.g., "Today, as you } \\
\text { read about the main character's house, be thinking about } \\
\text { those details. The setting is going to play a pivotal role in } \\
\text { this book. As you read, put a post-it note next to important } \\
\text { details and be ready to discuss them afterwards.") } \\
\text { If text is nonfiction, key technical vocabulary should be } \\
\text { explicitly defined in child-friendly terms. (e.g., "In today's } \\
\text { text, we will read about the water cycle. You will see three } \\
\text { words that you might not have seen before. They include } \\
\text { evaporation, condensation, and precipitation. I have three } \\
\text { pictures here to help us. Look at the picture as I define each } \\
\text { term....") }\end{array}$ & $\begin{array}{l}2 \\
\text { minutes }\end{array}$ \\
\hline Reading & Students read silently or in pairs. & $\begin{array}{l}10 \\
\text { minutes }\end{array}$ \\
\hline Discussion & $\begin{array}{l}\text { Teacher should present some questions for students to } \\
\text { discuss in pairs. Additionally, if fiction, explicit discussion } \\
\text { of vocabulary could be included. If nonfiction, vocabulary } \\
\text { should be reviewed again. }\end{array}$ & $\begin{array}{l}4 \\
\text { minutes }\end{array}$ \\
\hline
\end{tabular}

